\title{
An Interdisciplinary Project-Based Service Learning and Action Research Project with Mechanical Engineering and Speech-Language Pathology Students
}

\section{Dr. James D Carrico, University of Mary}

James Carrico is an Assistant Professor at the University of Mary. He received his $\mathrm{PhD}$ in Mechanical Engineering from the University of Utah in 2018. The focus of his doctoral studies was the design, 3D printing, and control of ionic polymer-metal composite (IPMC) actuators, for use in soft robotics. His interests include engineering education, design, active polymers, additive manufacturing, and assistive technology.

\section{Dr. Javad Anjum, University of Mary}

Javad Anjum is an Assistant Professor at the University of Mary. He worked as a physician in India and pursued clinical research in Neurophysiology. He then completed a PhD in Speech-Language Science from the Ohio University with research foci in aphasia and psycholinguistics. Javad's current research interests are in understanding the impaired and unimpaired cognitive-linguistic processes in aphasia and developing assessment methods for evaluating language performance in people with brain injuries. $\mathrm{He}$ also has research interests in interprofessional education (IPE) with health sciences and engineering disciplines.

\section{Ms. Audra Anjum, Ohio University}

Audra Anjum is an instructional designer in the Russ College of Engineering and Technology at Ohio University, Athens, Ohio. She works with faculty to design and redesign courses while following best practices in technology integration. Her research interests include learning aptitudes and facilitating classroom communication. 


\title{
An Interdisciplinary Project-Based Service Learning and Action Research Project with Mechanical Engineering and Speech-Language Pathology Students
}

\begin{abstract}
The current paper addresses an imminent need for an action research study to systematically investigate the effectiveness of an interprofessional project-based service-learning experience in fostering collaboration, deep learning, teamwork, and communication between Mechanical Engineering (ME) and Speech Language Pathology (SLP) students. In the project, junior or senior level ME students collaborate with SLP students to develop manufacturing processes (especially utilizing $3 \mathrm{D}$ printing and other polymer processing methods) for in-house fabrication of low-cost, custom-made therapeutic material, for use at the SLP clinic and in the community. A convergent, parallel, mixed-methods approach was used to evaluate the design, implementation, and student experiences associated with this project, with particular emphasis on learning orientation and professional skills (especially teamwork and communication). The parallel collection of qualitative and quantitative data was accomplished through weekly questionnaires and indexing of team communications on a communication tool called Slack.

Analyses and thematic classification of the self-reported questionnaire data and the student-generated Slack transcripts revealed that while the interprofessional PBSL project contributed to positive student attitudes, there was a mis-match in intended outcomes and student efforts. Consequently, interprofessional communication and focus on the project was irregular. Themes including interest in course content, a desire to collaborate with others, preparation for professional practice, a desire to help others, a desire to demonstrate one's own abilities, and a desire to keep professional commitments contributed to positive student attitude and motivation to excel. Challenges to collaboration included scheduling times to meet, understanding collaborator expectations, and meeting those expectations. For educators interested in including a interprofessional PBSL project in their course, we advise that project deliverables should match the technical outcomes of the course (e.g. an interprofessional PBSL project in a manufacturing class should explicitly involve a manufacturing problem); the interprofessional PBSL project should be fully integrated into the class, such that technical content is instrumental to completion of the project; and regular interprofessional meeting times should be built into the class schedule.
\end{abstract}

\section{Introduction}

This paper examines the effectiveness of interprofessional project-based service learning (PBSL) experience in fostering a deep orientation to learning, and professional skills (especially communication and teamwork). Learning orientation describes a student's attitude towards and motivation for studying. It is desirable that engineering students adopt a so-called deep learning orientation, emphasizing understanding as well as reflection on the applicability of course content 
and the transferability of learning experiences to professional settings ${ }^{5}$. The need for a focus on professional skills has been emphasized since the 1990s due to the preponderance of engineering jobs being in commercial industry, where the ability to function as part of a cross-disciplinary team and to understand how non-technical factors influence engineering decisions is especially crucial $^{24}$. Since EC 2000, these broader considerations have been incorporated into ABET a-k criteria which establish what student outcomes are required for ABET accredited engineering programs $^{6}$. So it is especially crucial to establish meaningful mechanisms to foster and evaluate these professional skills. In spite of these exigencies, it is by no means guaranteed that engineering students will adopt a deep learning orientation and new engineers often report not being well-prepared for the social complexity or distributed expertise of the workplace ${ }^{15}$.

There is research to show that well-thought-out (PBSL) experiences fosters a deeper orientation to studying and professional skills ${ }^{21,9,17,28,15}$. PBSL is an instructional approach typically involving teams of students working together to solve a problem or to address a need in the community. PBSL experiences provide students with opportunities to engage in supervised, yet authentic, professional communication and problem-solving scenarios with real-world benefits. Programs like the Engineering Projects in Community Service (EPICS) program at Purdue University have been shown to foster student preparedness for the workplace, based on surveys and interviews of alumni ${ }^{15}$. In surveys of alumni, over $75 \%$ of the 523 alumni surveyed credited the EPICS program with improving their professional skills such as their "ability to work with people from very different disciplines", "ability to demonstrate leadership in a team environment", and "ability to effectively communicate my ideas to customers" 15 . The characteristics of the EPICS program highlighted as important for these outcomes and experiences are the fact that it is a real project with real stake holders and consequences, that the projects are open-ended (ill-defined) and student-led, and that it involves multiple disciplines. These characteristics are credited with giving the projects their authenticity. Integrating a student-centered interprofessional component into an existing PBSL framework is consistent with the need for multi-disciplinary involvement emphasized in the study of the EPICs program. This lends authenticity to the project since real-world problems are generally multifaceted, requiring collaboration between groups with diverse competencies across multiple disciplines.

The benefits of interprofessional education ${ }^{2}$ and collaborative learning ${ }^{27}$ in engineering are well-established. Interprofessional learning experiences, especially those from diverse fields, expose students to variability among how potential collaborators discuss problems and value knowledge as well as their expectations for communication and consensus ${ }^{2}$. Collaborative learning, especially in the form of small groups, is shown to be effective in promoting greater academic achievement, more favorable attitudes toward learning, and increased persistence ${ }^{25}$. Integrating interprofessional projects into existing PBSL efforts may offer two additional advantages. First, since students are addressing concrete needs in an interprofessional working environment, the interprofessional PBSL experience may help foster mature attitudes towards professional practice. Second, the array of challenges, joys, and rewards associated with serving the community in an interprofessional team may promote career readiness and confidence in one's training and aptitude.

The need for interprofessional education and collaborative practice is not unique to engineering. Training programs for pre-service professionals in allied health specialties, such as clinical 
exercise physiology, physical therapy, occupational therapy, and athletic training, benefit from interprofessional experiences as well. The need for inculcating interprofessional learning experiences into the pre-service training in allied health professions has been mainly furnished through mandating accreditation standards related to interprofessional education ${ }^{1,18,19}$. A motivation behind this initiative is to replicate real-life contexts of catering to the needs of real people, into training modules that require students to collaborate, communicate, exchange knowledge, and apply their learning experiences to solve problems. To this end, rehabilitative clinicians (e.g., SLP students) and engineers (e.g., mechanical engineers) form an important part of our societal work force, wherein both professionals are continuously working in their respective fields of practice in the service of making human lives better. They often work collaboratively in the field to design therapy materials for use in the clinics and the community.

The shared need for interprofessional and collaborative education, the breadth of instruments used in therapeutic settings, and the prevalence of health problems that warrant innovation and design recommends joint endeavors between engineering students and health science students to enrich instruction ${ }^{12}$. However, these opportunities seem to be under-utilized. Notably, there have been at least two such collaborative studies. One such study was conducted between occupational therapy and engineering students and involved designing custom therapeutic devices requested by elderly patients in senior care facilities ${ }^{4}$. In that project, there was a self-reported increase in communication, teamwork, and conflict resolution skills and an increase in confidence in addressing clinical and technical problems. Another similar study was conducted between physical therapy, SLP, and engineering students and faculty and involved designing and delivering two low-cost communication devices to four children with communication difficulties (nonverbal) living in an orphanage in Ecuador ${ }^{14}$. However, in these studies, exchanges between the collaborating students were not tracked and analyzed. So independent measures of communication skills, teamwork, and conflict resolution, were not reported, which would have provided additional insight for the purpose of designing similar action research studies across different disciplines.

\section{Purpose statement}

The purpose of the current study was to systematically document and analyze the effectiveness of a semester-long interprofessional PBSL experience at fostering collaboration, a deep learning orientation, teamwork, and communication between ME and SLP students. In this pilot study, a mixed-methods research approach was used to evaluate the design, implementation, and student experiences associated with this project ${ }^{3}$. The parallel collection of qualitative and quantitative data was accomplished through weekly questionnaires and indexing of team communications on a communication tool called Slack.

\section{Guiding research questions}

This paper addresses a number of research questions on the effect of interprofessional PBSL projects on learning orientation, communication skills, and teamwork. 
1. How do various aspects of the interprofessional PBSL project (e.g. it's interprofessional and service aspects) influence attitude and motivation towards course material?

2. How do engineering students balance interprofessional aspects of their coursework with technical aspects?

3. What communication challenges do engineering students face when collaborating with SLP students on a PBSL project?

\section{Instructional design}

Our action research team included a ME faculty member, a SLP faculty member, and an instructional designer. Elements of the interprofessional PBSL project were designed to align with student outcomes for both SLP and ME programs. As part of a goal-scenario framework, SLP students functioned as clinicians and were tasked with coming up with the fundamental purpose and design of custom therapeutic devices. ME students worked with SLP students to define functional requirements and to develop specific solutions. ME students were also tasked with defining an expedient and economic manufacturing method to realize the designs. The project was developed as part of a curriculum that supports ABET student outcomes:

c. An ability to design a system, component, or process to meet desired needs within realistic constraints such as economic, environmental, social, political, ethical, health and safety, restructurability, and sustainability.

d. An ability to function on multidisciplinary teams

g. An ability to communicate effectively (both orally and written)

k. An ability to use the techniques, skills, and modern engineering tools necessary for engineering practice.

ME students in their junior or senior years are especially suited for working in interprofessional PBSL projects with rehabilitation professionals such as SLP students due to the ME students' course preparation and potential for future collaboration with rehabilitation professionals. Specifically, juniors and seniors in ME have already completed sufficient coursework in materials, design, and manufacturing processes, to be prepared to collaborate with SLP students, who require a wide array of therapeutic materials in their clinical practice. Also, such collaborations between ME students and SLP students may foster a favorable attitude toward industries that serve people with disabilities and inspire ME students to pursue collaboration with rehabilitation professionals in their future careers ${ }^{7}$. Textual analysis of student communications within and across the teams offers a novel lens through which educational researchers can ground student-reported experiences in actual student communicative and collaborative efforts. The faculty members conducting the action research study included Slack in their instructional design for the following reasons, (a) interprofessional communication was expected throughout all aspects of the project, (b) providing a standard platform of communication (as mandated by the faculty) set the tone for professional communication as opposed to group texts, etc., (c) prescribing a platform that afforded student-student communication while maintaining visibility 
to faculty so that faculty could intervene with formative feedback in a specific and timely manner, as opposed to off-Slack conversations, which were not visible to faculty.

\section{Research design}

Secondary to the instructional design was the research design. The evaluative portion of the overall project was done as a collaborative action research project. Action research is an approach to inquiry conducted by and for those engaged in a real-world phenomenon, such as a classroom setting ${ }^{20}$. Action research in higher education is a commonly employed practice for institutional development, curriculum development, and teacher training ${ }^{8}$. A convergent, parallel, mixed-methods approach was used to address the guiding research questions ${ }^{3}$. The parallel collection of qualitative and quantitative data was accomplished through the administration of questionnaires to the students and tracking team communications of students via Slack.

A course from each discipline (ME and SLP) was selected for this exploratory pilot based on the alignment of the courses' learning objectives, scheduling, and enrollment size. A purposive sample was recruited based on students' enrollment in the specific ME and SLP courses selected. We obtained informed consent from all students enrolled in each course, but we have included results only from those who were enrolled throughout the duration of the semester. Four seniors in the ME program (one female and three males) and 17 first-year graduate students in the SLP program (all female) participated in this project. Three groups were formed with six SLP students in each. Two of the groups had one ME student each and one of the groups had two ME students. Each group had a separate project.

Procedure: The project consisted of five milestones that included class meetings and presentations by students and/or instructors. At the first milestone, informed consent was obtained and SLP-EME student teams were formed. A baseline questionnaire was administered and the ME instructor gave a lecture on therapeutic applications of 3D printing. Then, the messaging communication tool Slack was introduced to all student groups. During the second milestone, the SLP instructor and student clinicians (SLP students) introduced client personas (potential client needs, based composite client profiles) to ME students and shortly thereafter submitted needs analysis documents and provided design requirements to the ME students, based on client personas. In the third milestone, ME students presented prototypes to student clinicians. The SLP instructor and students reviewed the models and provided feedback. Students across all groups collaborated on Slack to refine requirements. At the final milestone, the ME students integrated the feedback and presented the prototypes again. At the end of the semester, both ME and SLP students presented their work to their respective departments. In addition to using Slack as the primary communication platform for students and faculty, students also completed weekly questionnaires. The questionnaires consisted of the following questions:

1. Rate your interest in this course content.

2. How motivated are you to excel in this course?

3. Briefly explain what motivates you to learn the course material.

4. How motivated are you to excel in this project? 
5. Briefly explain what motivates you to complete the class project.

6. How often do your interprofessional teammates (ME/SLP) communicate with you on a weekly basis?

7. How often do your professional teammates (ME or SLP) communicate with you on a weekly basis?

8. How clear were your interprofessional teammates (ME/SLP) during communication activities this week?

9. How clear were your weekly professional teammates (ME or SLP) during communication activities this week?

10. How do you rate your own communication skills?

11. What challenges did you experience communicating with your teams this week?

12. How did your interprofessional team (ME/SLP) delegate tasks/divide work this week?

13. How did your professional team (ME or SLP) delegate tasks/divide work this week?

14. How did you contribute to your teams this week? NOTE: we recognize that not all weeks will require your specific contributions.

Questions 1, 2, 4, and 6-10 are scaled (1-10) and questions 3, 5, and 11-14 are open-ended questions requiring the student to write in a response. The questionnaire was administered nine times during the course of the semester during weeks $3-5,7-10,14$, and 15 .

Analysis: Questions 1-5 give insight into students' learning orientation and to what extent students adopt a service mindset and are motivated by unique aspects of the interprofessional PBSL project, such as its interprofessional and/or service components. Questions 6-14 give insight into students' communication and teamwork skills.

The analysis of qualitative data was conducted in two phases: a conventional content analysis of ME student responses to the open-ended questionnaire items (Phase I) and a directed content analysis of the ME student-generated Slack transcripts (Phase II). In Phase I, responses were pooled for each open-ended question (3,5, and 11-14). We conducted an initial, conventional content analysis to avoid potential confirmation bias from working with an existing theoretical framework (we later did this in Phase II). As codes emerged, they were arranged into themes, which are represented per question in the results section of this paper. For Phase II, the semester-long Slack chat transcripts were downloaded, separated by week (Monday through Sunday), and imported into MaxQDA ${ }^{11}$. We conducted a first pass through the transcripts to work through any decisions concerning operationalization of utterances and activity. To determine a unit of analysis, we modeled unit construction after Strijbos and Stahl's ${ }^{26}$ guidelines for handling 'unit fragmentation', as our students frequently provided multiple lines of fragmented messages that needed to be considered as one unit in order to be meaningful and to express a complete activity or intention. Based on the nature of peer interactions, an utterance (unit of analysis) was operationalized as a student sending a message or a string of messages in uninterrupted succession. Interruptions include (a) a message from another person in the same channel or (b) five minutes of inactivity. 
In line with a directed content analysis, we used the themes generated from the communication questions in Phase I as a priori codes in Phase II. Each identified utterance was either tagged with an existing code, or a new code was generated to capture behavior that did not manifest in the student self-reported data. A single utterance could not fall into the same code more than once, though it could fall into multiple codes at the same time, as we found that some utterances expressed more than one observable behavior. This approach differs from Strijbos and Stahl ${ }^{26}$, who found that their "chat users tended to only 'do' one thing in a given chat line".

\section{Results}

The following section first reports a timeline of interprofessional meetings, deliverables and other relevant evens like exam dates. Next, this section reports historical survey data on ME students' self-reported interest and motivation in class content and the interprofessional project, followed by historical survey data on ME students' self-reported and collaborator-reported communication and teamwork skills. The data on teamwork and communication is augmented with and compared to Slack data.

Timeline: Table 1 gives a list of codes for the time-line illustrated in Fig. 1. The time-line lists when questionnaires were administered, when the ME students had exams, when there were interprofessional meetings, and when deliverables were assigned or submitted. Additionally, since two of the ME students were part of a school athletics team, the time-line also lists athletic events that required travel as well as the end of the season. 
Table 1: Codes for timeline in Fig. 1

\begin{tabular}{ll}
\hline Code & Description \\
\hline $\mathrm{Q}$ & Administration of a questionnaire \\
$\mathrm{X} 1$ & Midterm exam \\
$\mathrm{X} 2$ & Final exam \\
M1 & In-person interprofessional meeting with SLP collaborators \\
M2 & Interprofessional meeting moved on-line due to class cancellation \\
A1 & Athletic events that required travel from two ME students \\
A2 & End of athletics season \\
D1 & Informed consent administered \\
D2 & ME instructor gives presentation on 3D printing and theraputic devices \\
D3 & Client personas presented by SLP \\
D4 & Needs assessment documents submitted by SLP students and shared with ME students \\
D5 & ME presented printed prototypes \\
D6 & SLP present finished products \\
D7 & ME instructor gives presentation on low volume manufacturing to SLP students
\end{tabular}

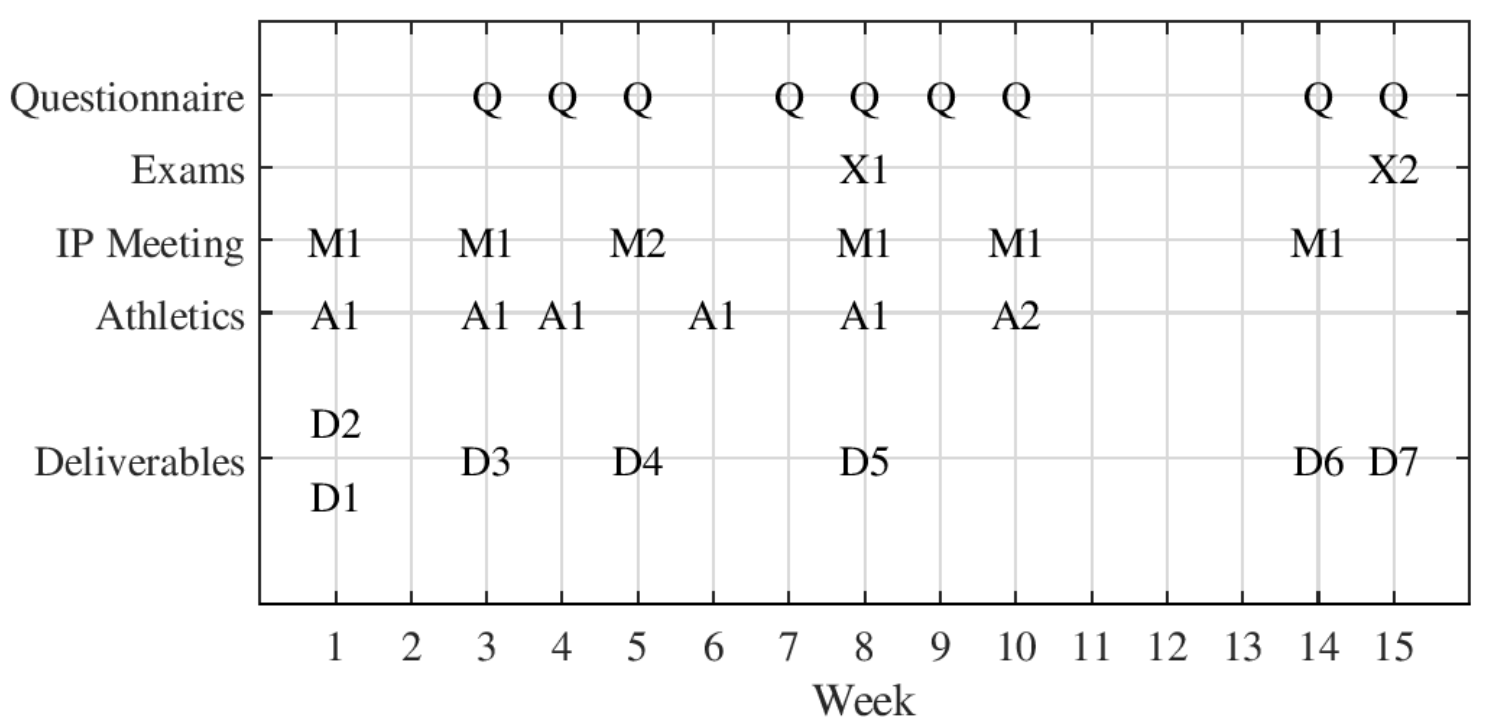

Figure 1: Timeline of events including when questionnaires were administered, when the ME students had exams, when there were interprofessional meetings, when there were athletic events that affected ME students and when events related to the project occurred. 


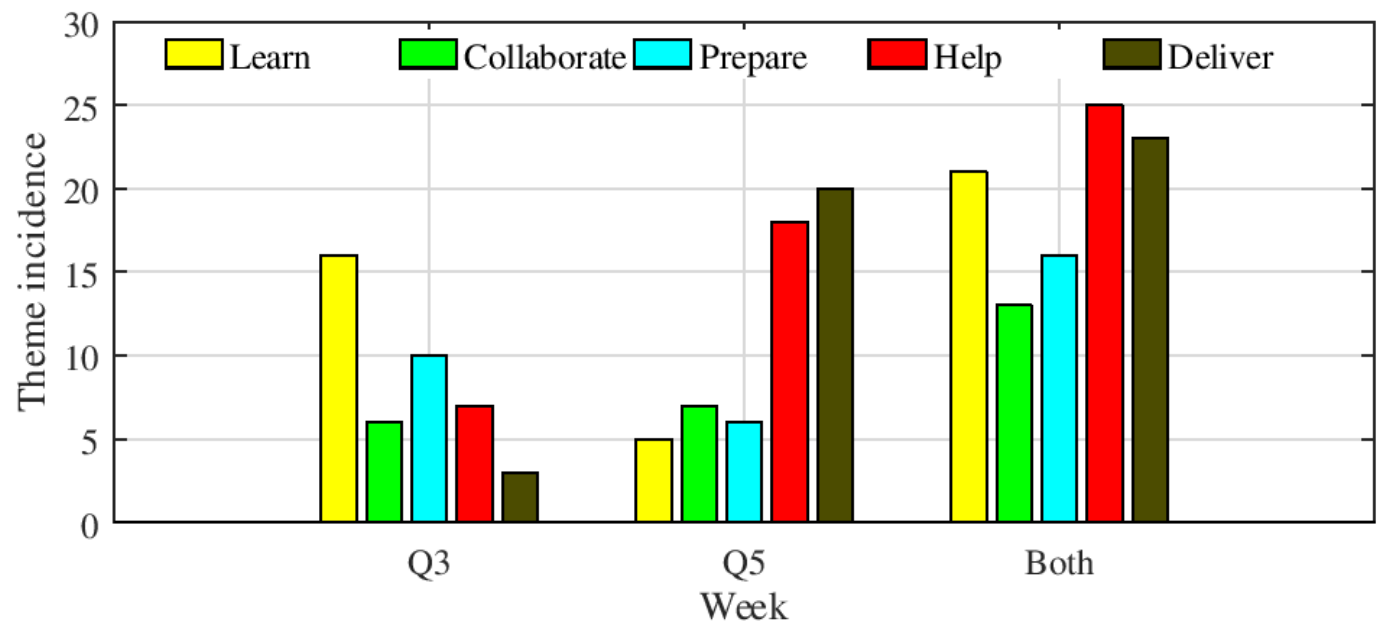

Figure 2: Total incidence of top five most frequent themes from responses of ME students in response to question 3 (Briefly explain what motivates you to learn the course material.) and question 5 (Briefly explain what motivates you to complete the class project.)

As shown in Tbl. 1 and Fig. 1, interprofessional meetings were conducted fairly regularly throughout the semester. A questionnaire was first administered the same week the client personas were submitted by the SLP students (in week 3). Questionnaires were administered almost uninterruptedly until after the ME students presented their prototypes (in week 8). Questionnaires were also administered when ME and SLP students met with occupational therapy clients and clinicians, and the ME students took on additional design tasks (in week 10). Questionnaires were also administered when SLP students presented their finished products and when ME students delivered prototypes to the occupational therapy clinicians (in week 14). The ME students had a midterm exam in week 8 and their final was given in week 15 .

Interest and motivation: The top of Fig. 3 gives the weekly mean ratings of the ME students' responses to question 1 (Rate your interest in this course content.) The bottom of Fig. 3 gives the weekly mean responses of the ME students and SLP to question 2 (How motivated are you to excel in this course?) and question 4 (How motivated are you to excel in this project?). Table 2 gives the codes for thematic analysis of question 3 (Briefly explain what motivates you to learn the course material.), and Tbl. 3 gives the codes for thematic analysis of question 5 (Briefly explain what motivates you to complete the class project.) and their description. Figure 4 gives the weekly incidence of top five most frequent themes from responses of ME students in response to question 3. Figure 5 gives the weekly incidence of top five most frequent themes from responses of ME students in response to question 5. Figure 2 gives thee total incidence of top five most frequent themes from responses of ME students in response to question 3 and question 5.

As shown in Fig. 3, the ME students consistently rate their interest in course content and motivation-to-excel to be high (with a mean rating above 7) throughout the semester. But the ME students consistently rate their motivation-to-excel to be higher for the project than for the course as a whole. There is an apparent increase in interest in course content mid-semester as well as in the final two weeks. There is an apparent decrease in interest and motivation at week 10. As shown in Fig. 4, a desire to collaborate is high at the beginning of the project (week 3). This drops 

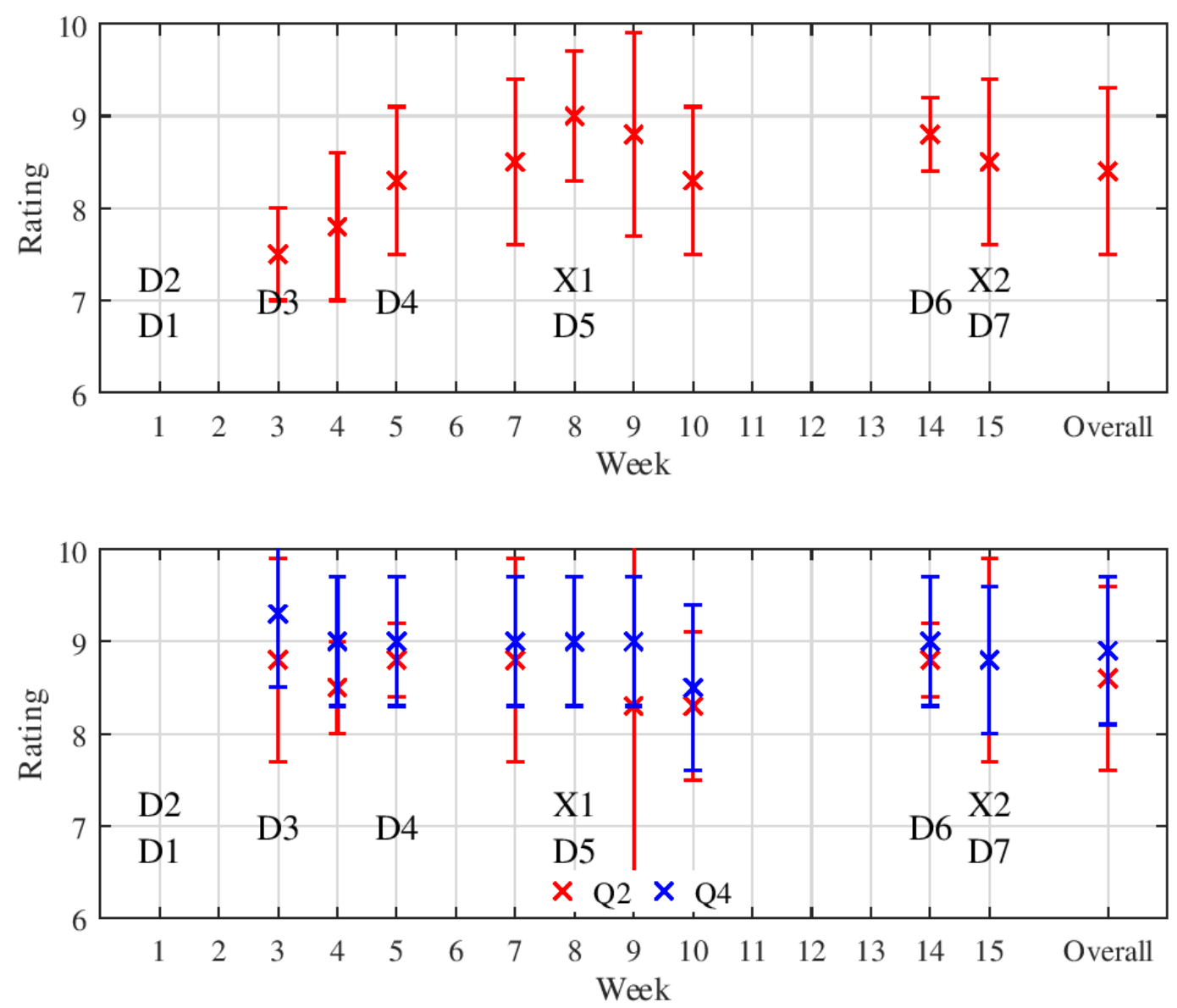

Figure 3: Weekly mean ratings from question 1 (Rate your interest in this course content) of questionnaire (top) and of question 2 (How motivated are you to excel in this course?) and question 4 (How motivated are you to excel in this project?) (bottom) administered to ME students. Error bars indicate the population standard deviation.

off at week 7 and a desire to create becomes more expressed. A desire to help is first expressed in week 8 and continues to be expressed through to the end of the project. A simple desire to learn and to prepare remains prominent throughout and is predominant towards the beginning and end of the course as motivators to learn course content.

As shown in Fig. 5, a desire to help and a desire to deliver are strongly expressed motivations to-excel in the project throughout the semester. A desire to prepare is also expressed throughout. A desire to learn is occasionally expressed as a motivation up through week 8 . A desire to collaborate is first expressed at week 5 and and is strongly emphasized at weeks 9 and 14. As shown in Fig. 2, a simple desire to learn and to prepare are the most frequently expressed themes in response to question 3, but a desire to help and to deliver are the predominant themes in response to question 5 and the total combined incidence of questions 3 and 5 . 
Table 2: Thematic analysis codes for question 3 (Briefly explain what motivates you to learn the course material.)

\begin{tabular}{ll}
\hline Code & Description \\
\hline Learn & Answers that highlight simple interest-in/desire-to-learn course material \\
Collaborate & Answers that highlight a desire to work with other disciplines \\
Prepare & Answers that highlight a desire for professional perperation \\
Create & Answers that highlight a desire to create things (especially physical products) \\
Help & Answers that highlight a desire to help others \\
Pass & Answers that highlight a desire to get good grades or meet acedemic expectations \\
Deliver & Answers that highlight a desire to deliver a product that meets/exceeds expectations \\
Enjoy & Answers that highlight a desire to have fun
\end{tabular}
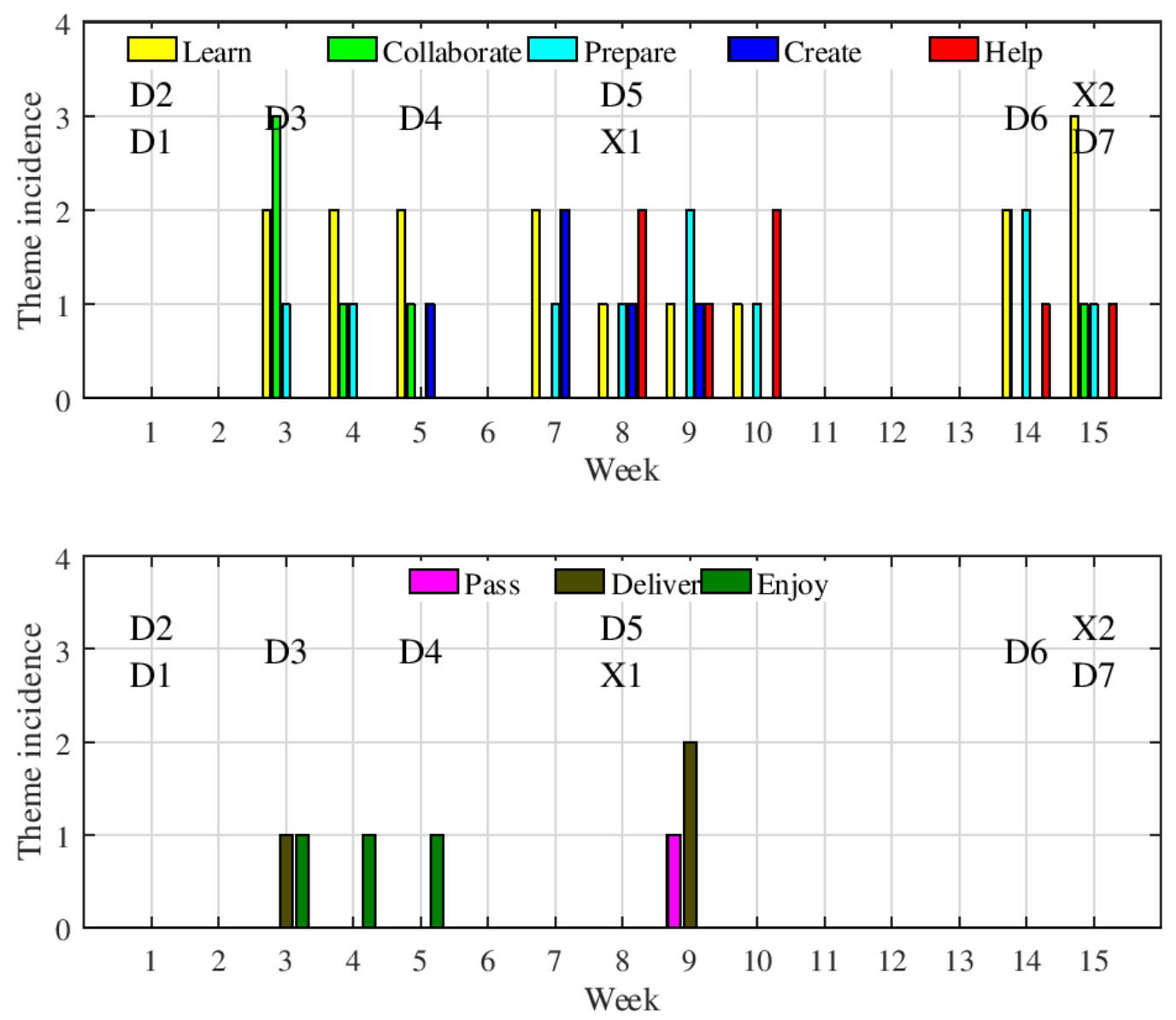

Figure 4: Weekly incidence themes from responses of ME students to question 3 (Briefly explain what motivates you to learn the course material.) 
Table 3: Thematic analysis codes for question 5 (Briefly explain what motivates you to complete the class project.)

\begin{tabular}{ll}
\hline Code & Description \\
\hline Learn & Answers that highlight simple interest-in/desire-to-learn course material \\
Collaborate & Answers that highlight a desire to work with other disciplines \\
Prepare & Answers that highlight a desire for professional perperation \\
Create & Answers that highlight a desire to create things (especially physical products) \\
Help & Answers that highlight a desire to help others \\
Pass & Answers that highlight a desire to get good grades or meet acedemic expectations \\
Deliver & Answers that highlight a desire to deliver a product that meets/exceeds expectations \\
Enjoy & Answers that highlight a desire to have fun
\end{tabular}
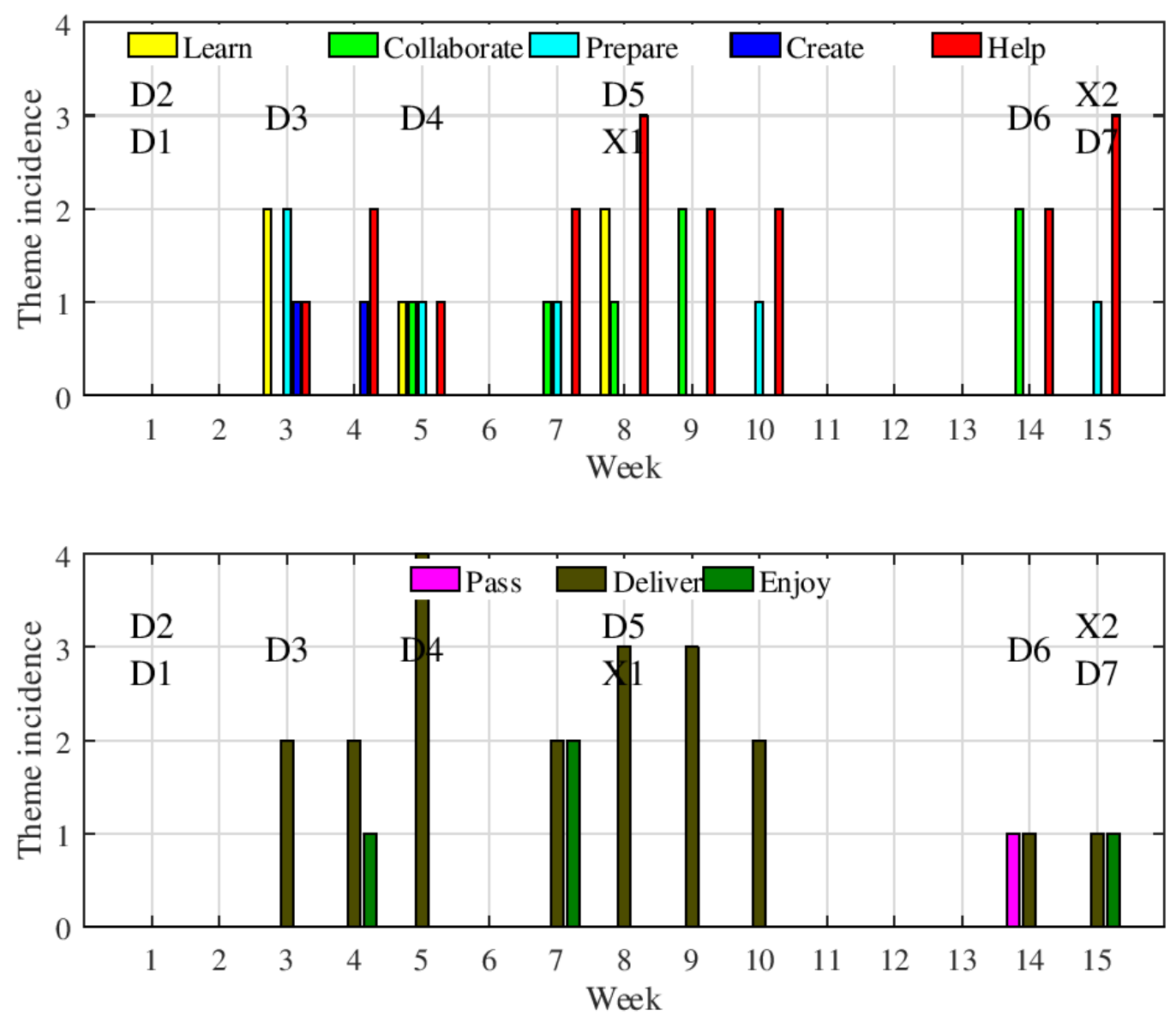

Figure 5: Weekly incidence themes from responses of ME students to question 5 (Briefly explain what motivates you to complete the class project.) 

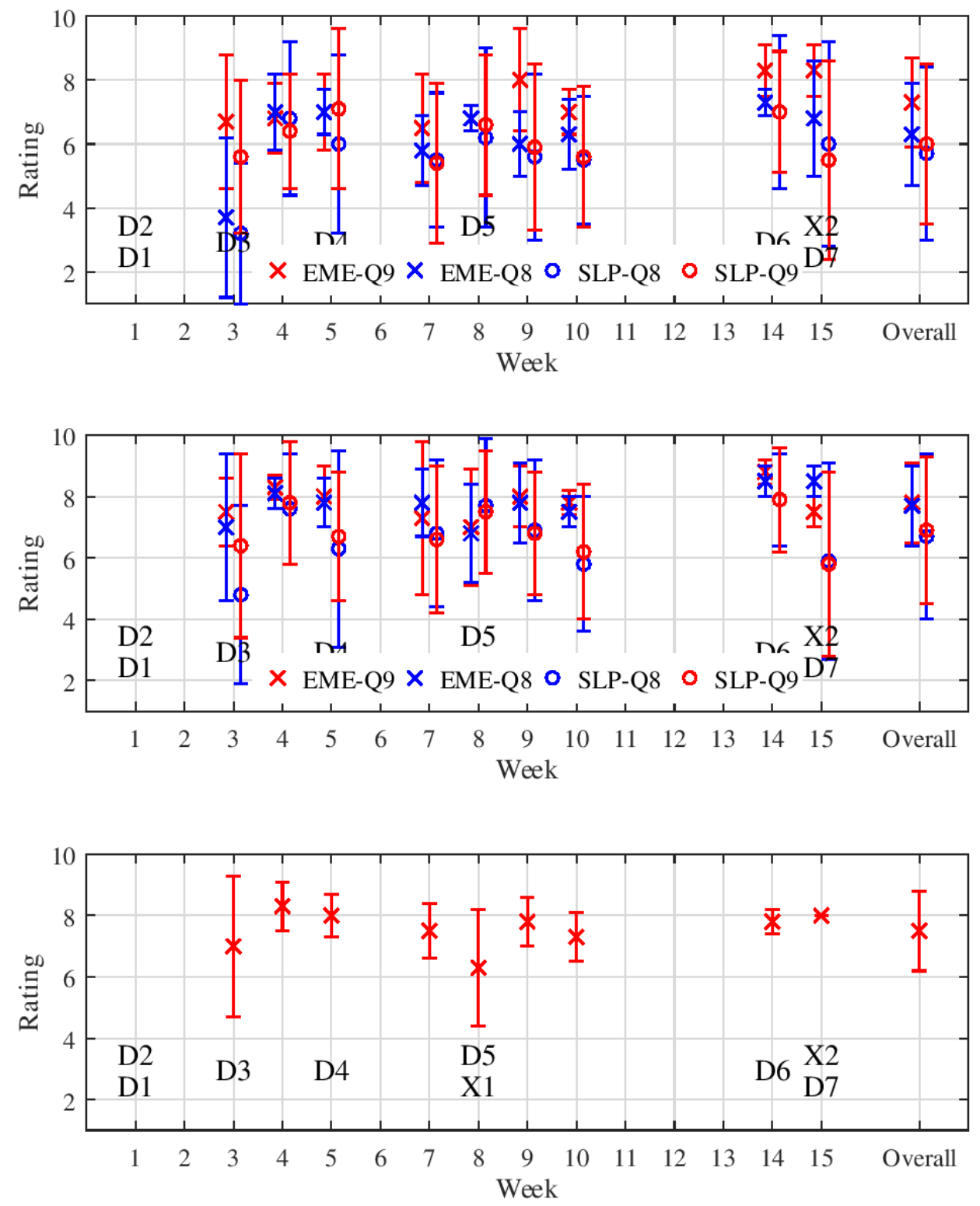

Figure 6: Weekly mean ratings from questions administered to both ME and SLP students: (top) question 6 (How often do your interprofessional teammates (ME/SLP) communicate with you on a weekly basis?) and question 7 (How often do your professional teammates (ME or SLP) communicate with you on a weekly basis?); (middle) question 8 (How clear were your interprofessional teammates (ME/SLP) during communication activities this week?) and question 9 (How clear were your weekly professional teammates (ME or SLP) during communication activities this week?) of the questionnaire administered; (bottom) question 10 - administered just to $\mathrm{ME}$ (How do you rate your own communication skills?). Error bars indicate the population standard deviation. 
Teamwork and communication: The top of Fig. 6 gives the weekly mean ratings of the ME students and SLP students' responses to question 6 (How often do your interprofessional teammates (ME/SLP) communicate with you on a weekly basis?) and question 7 (How often do your professional teammates (ME or SLP) communicate with you on a weekly basis?) The bottom of Fig. 6 gives the weekly mean ratings of the ME students and SLP students' responses to question 8 (How clear were your interprofessional teammates (ME/SLP) during communication activities this week?), question 9 (How clear were your weekly professional teammates (ME or SLP) during communication activities this week?), and question 10 (How do you rate your own communication skills?). Table 4 gives the codes for thematic analysis of question 11 (What challenges did you experience communicating with your teams this week?). Figure 7 gives the weekly incidence of these themes. Figure 8 gives the weekly incidence of a subset of these same themes illustrated in Slack messages. Table 6 gives the codes for thematic analysis of question 12 (How did your interprofessional team (ME/SLP) delegate tasks/divide work this week?). Figure 9 gives the weekly incidence of themes from responses of ME students to question 12. Table 7 gives the codes for thematic analysis of question 14 (How did you contribute to your teams this week? NOTE: we recognize that not all weeks will require your specific contributions.) Figure 10 gives the weekly incidence of top five most frequent themes from responses of ME students in response to question 14. Figure 11 gives the weekly incidence of a subset of these same themes illustrated in Slack messages. Data from question 13 (How did your professional team (ME or $S L P$ ) delegate tasks/divide work this week?) is not included since ME students did not generally work with each other but only with a group of SLP students.

As shown in Fig. 6, the ME students generally rate both ME students and SLP students as communicating more frequently and more clearly than SLP students rate the same groups. There are exceptions to this in weeks five and eight. Generally, both ME students and SLP students rate their co-professionals to communicate more frequently and clearly than their interprofessional collaborators. There are exceptions to this in weeks four, seven, eight, and fifth-teen. SLP students rate ME students lowest on frequency and clarity of communication on week 3 and highest on weeks 4 and 8. ME students rank their own communication skills as lowest on weeks 3 and 8 and highest on week 4. As shown in Fig. 7, the themes with the highest incidence were themes E (Answers that highlight challenges, such as finding times to meet), $\mathrm{H}$ (Answers where the respondent answered N/A or not applicable), I (Answers where the respondent indicated there were no challenges), A (Answers highlighting challenges meeting SLP expectations as agreed) and $\mathrm{C}$ (Answers that highlight $\mathrm{ME}$ unresponsiveness). Themes $\mathrm{E}$ and $\mathrm{C}$ are predominant in weeks 3 through 5. Theme E continues in weeks seven through nine, but themes $\mathrm{A}$ and $\mathrm{H}$ become predominant. Themes $\mathrm{A}$ and $\mathrm{C}$ are present in weeks 10 through 15 but themes I and $\mathrm{H}$ are predominant. Comparing Fig. 7 to theme incidence from Slack messages in Fig. 8, the themes with the highest incidence were Themes $\mathrm{E}$ and $\mathrm{F}$. Theme $\mathrm{E}$ is predominant in weeks 3 and 5 and is present in weeks 4 and 14. Themes $\mathrm{F}$ is predominant in weeks 5 and is present in weeks 3 and 8 . Additionally, theme A is present in weeks 5, 7, and 8. Theme $\mathrm{C}$ is present in week 3 and theme $\mathrm{J}$ is present in week 3 and 5 . 
Table 4: Thematic analysis codes for question 11 (What challenges did you experience communicating with your teams this week?)

\begin{tabular}{ll}
\hline Code & Description \\
\hline A & Answers highlighting challenges meeting SLP expectations as agreed \\
B & Answers highlighting a lack of attempted communication \\
C & Answers that highlight ME unresponsiveness \\
D & Answers that highlight there being nothing to talk about \\
E & Answers that highlight challenges finding times to meet \\
F & Answers that highlight confusion/misunderstanding of SLP expectations \\
G & Answers that highlight busyness preventing communication \\
H & Answers where the respondent answered N/A or not applicable \\
I & Answers where the respondent indicated there were no challenges \\
J & Answers that highlight confusion with instruction
\end{tabular}
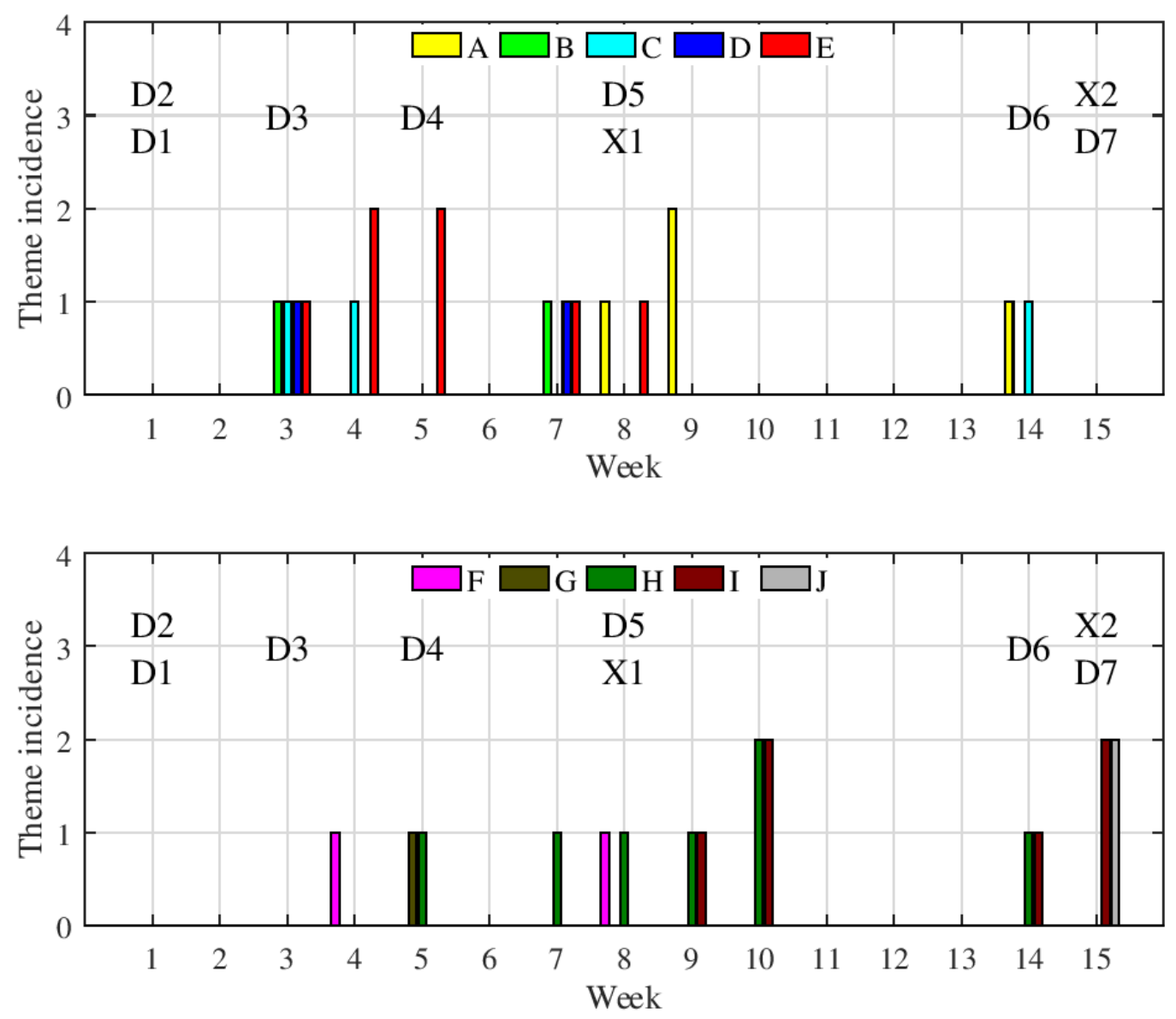

Figure 7: Weekly incidence of themes from responses of ME students to question 11 (What challenges did you experience communicating with your teams this week?) 
Table 5: Thematic analysis codes for communication challenges based on Slack messages

\begin{tabular}{ll}
\hline Code & Description \\
\hline A & Slack messages illustrating challenges meeting SLP expectations as agreed \\
C & Slack messages illustrating ME unresponsiveness even when properly pinged \\
E & Slack messages illustrating challenges finding times to meet \\
F & Slack messages illustrating confusion/misunderstanding of SLP expectations \\
G & Slack messages illustrating busyness preventing communication \\
J & Slack messages illustrating confusion with instruction \\
Z & Slack messages illustrating SLP students not properly pinging ME students in messages
\end{tabular}
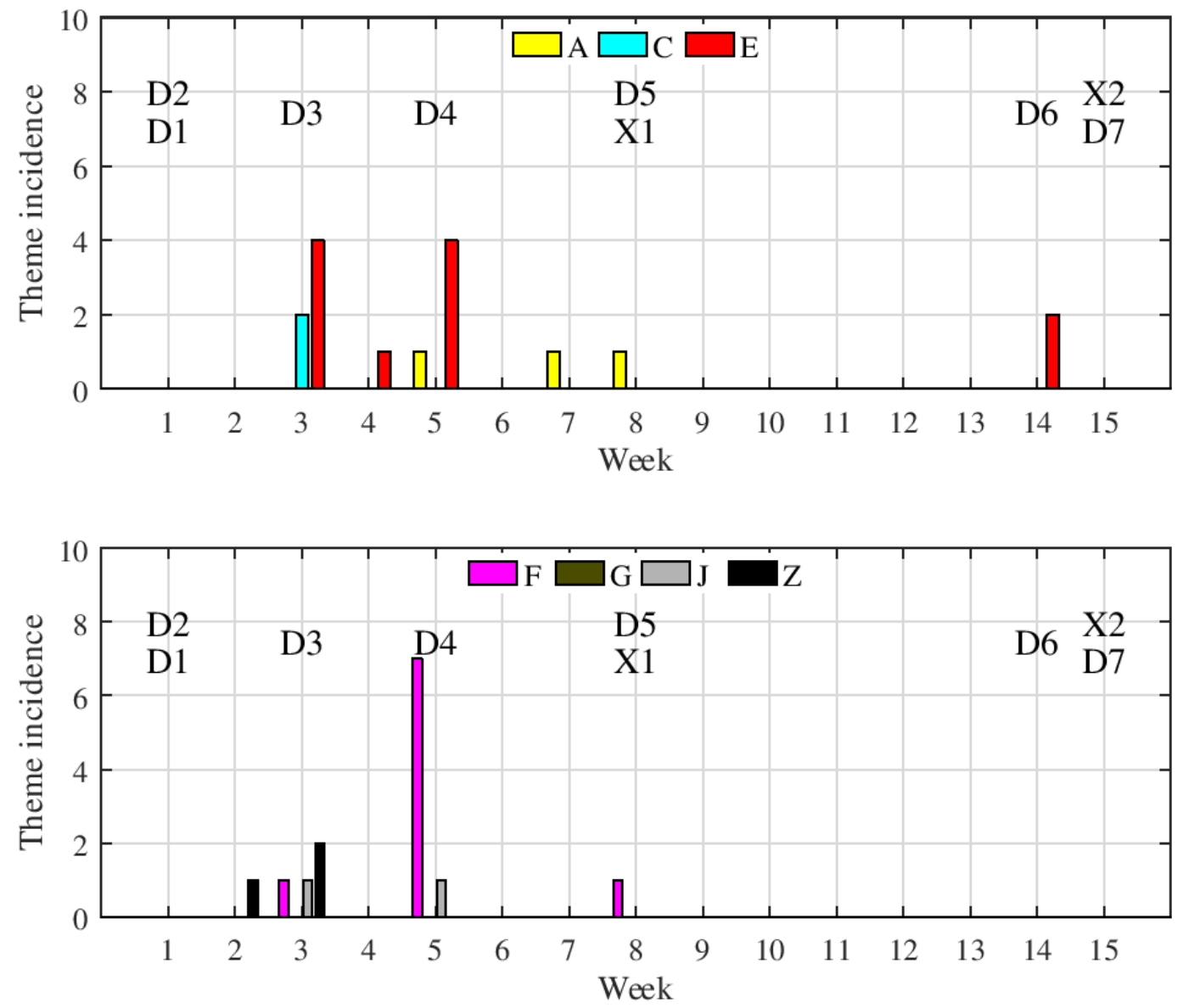

Figure 8: Weekly incidence of themes from ME Slack messages illustrating challenges to communication 
Table 6: Thematic analysis codes for question 12 (How did your interprofessional team (ME/SLP) delegate tasks/divide work this week?)

\begin{tabular}{ll}
\hline Code & Description \\
\hline A & Answers highlighting that work hasn't been divided/delegated \\
B & Answers highlighting what the respondent (EME) is doing \\
C & Answers where the respondent answered N/A or not applicable \\
D & Answers highlighting consulting of SLP collaborator \\
E & Answers that use phrases like "keep on working", "finish" or "continue on working on" \\
F & Answers highlighting not knowing what the SLP collaborator wants \\
G & Answers highlighting what the SLP collaborator is doing
\end{tabular}
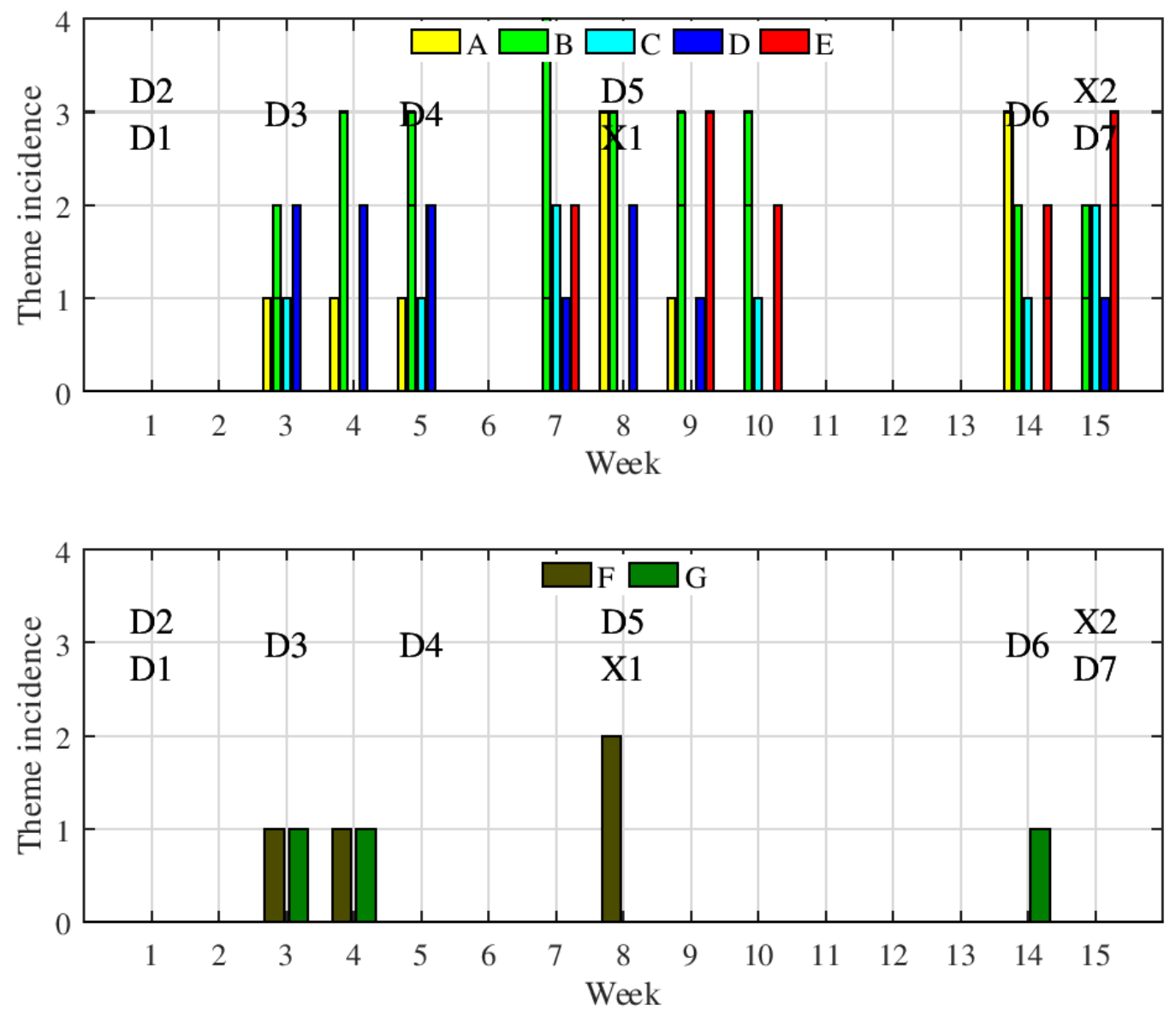

Figure 9: Weekly incidence of themes from responses of ME students to question 12 (How did your interprofessional team (ME/SLP) delegate tasks/divide work this week?) 
Table 7: Thematic analysis codes for question 14 (How did you contribute to your teams this week? NOTE: we recognize that not all weeks will require your specific contributions.)

\begin{tabular}{ll}
\hline Code & Description \\
\hline A & Answers highlighting work on fabrication \\
B & Answers highlighting work on designing/ideation \\
C & Answers where the respondent answered N/A or not applicable \\
D & Answers highlighting consulting of SLP collaborator \\
E & Answers that use phrases like "keep on working", "finish" or "continue on working on" \\
F & Answers highlighting work on a presentation \\
G & Answers highlighting that nothing was done
\end{tabular}
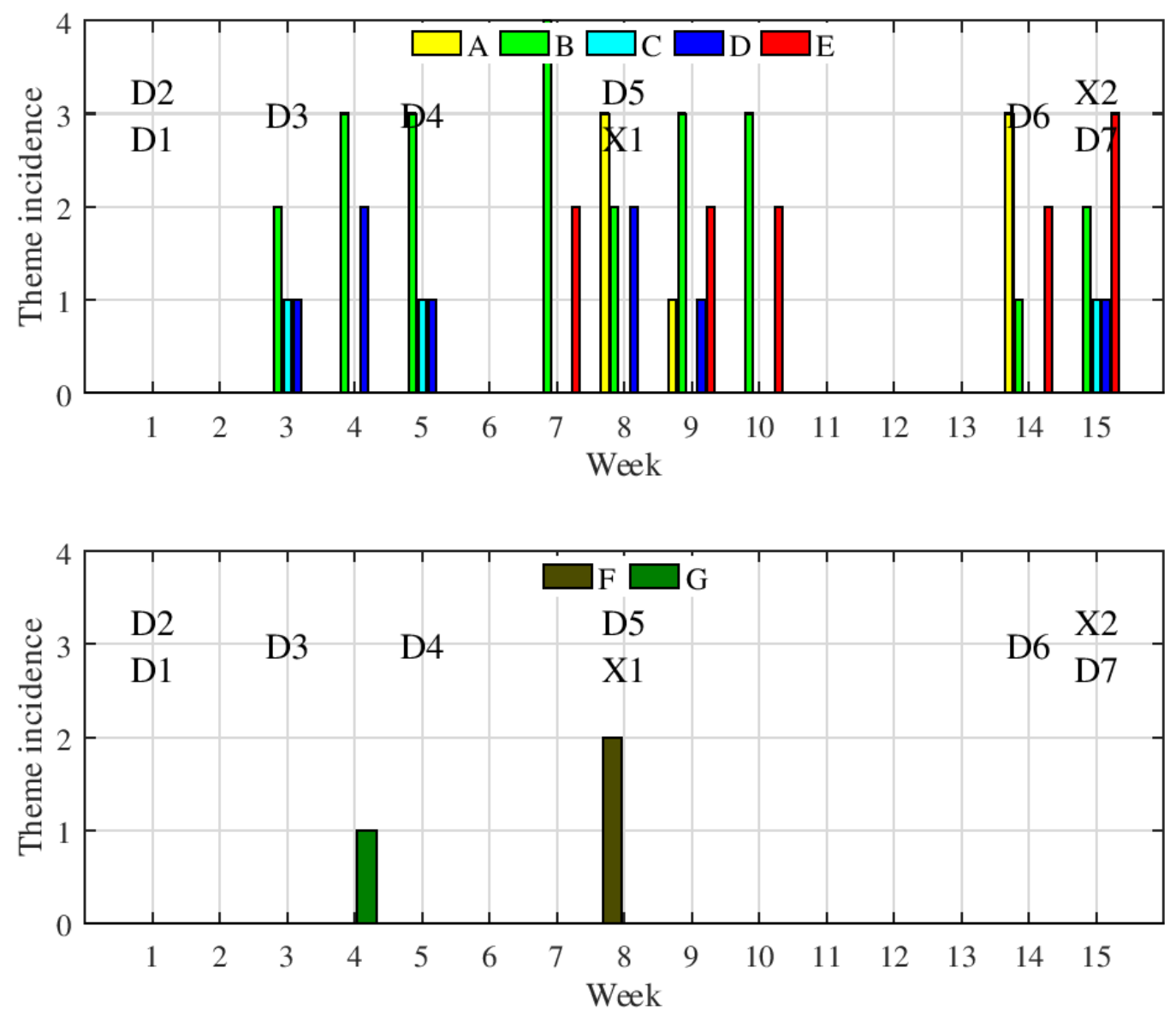

Figure 10: Weekly incidence of top five most frequent themes from responses of ME students to question 14 (How did you contribute to your teams this week? NOTE: we recognize that not all weeks will require your specific contributions.) 
Table 8: Thematic analysis codes for contribution based on Slack messages

\begin{tabular}{ll}
\hline Code & Description \\
\hline A & Slack messages illustrating work on fabrication \\
B & Slack messages illustrating work on designing/ideation \\
D & Slack messages illustrating consultation (i.e. every message) \\
E & Slack messages using phrases like "keep on working" or "finish" \\
F & Slack messages illustrating work on a presentation
\end{tabular}
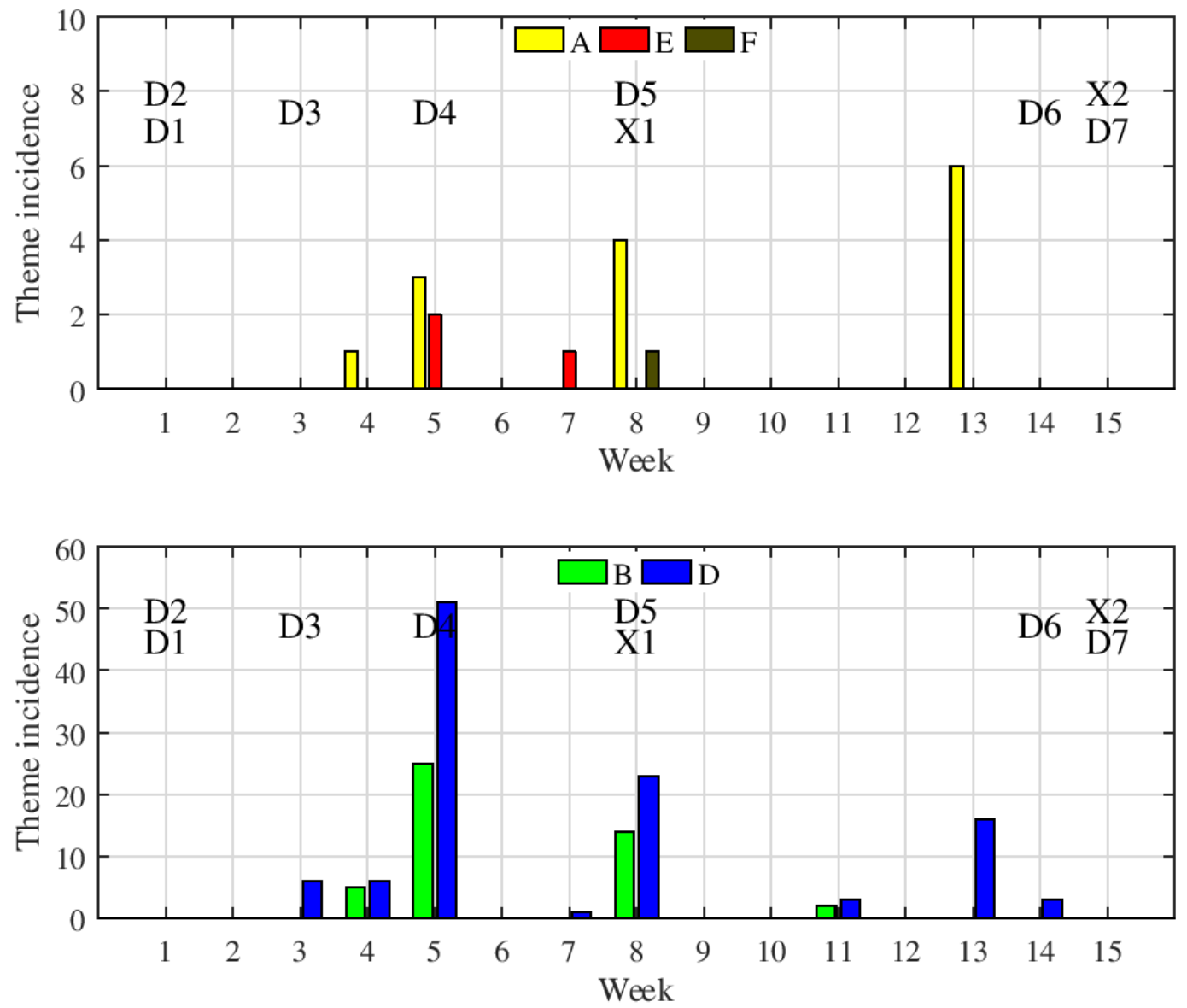

Figure 11: Weekly incidence of themes from ME Slack messages illustrating contribution 
As shown in Fig. 9, the ME students regularly discuss the tasks they are working on in response to question 12, in almost every survey. They also regularly indicate that they consult their SLP collaborators, again in almost every survey. Early on in the semester, their are some responses indicating that no tasks had yet been delegated, but this response is not made after week 5 . By week $9 \mathrm{ME}$ students make responses indicating that they are continuing on or finishing some on-going task. The code N/A or not applicable also appears in responses from weeks 3, 7, 10, 14, and 15. As shown in Fig. 10, responses indicating that ME students are contributing by either generating ideas and/or designing are predominant being the most frequent response almost every week. Responses indicating consulting with SLP collaborators also regularly appear. Responses indicating that ME students are contributing by fabricating something only appear in weeks 8, 9 and 14, though they are high frequency responses in weeks 8 and 14. Responses indicating that ME students are contributing by continuing on or finishing some on-going task appear in week 7 and remains present until week 15 (with the exception of week 8). Comparing Fig. 10 to theme incidence from Slack messages in Fig. 11, Slack messages coded as indicating that ME students are contributing by either generating ideas and/or designing are predominant and are present in weeks $4,5,8$, and 11 . The weekly total number of responses indicate that ME studets directly consulted with SLP students through Slack in weeks 3, 4, 5, 7, 8, 11, and 14. But a substantial volume of messages $(>10)$ was only seen on weeks 5, 8, and 13. Slack messages indicating ME students are contributing by fabricating something appear in weeks 4, 5, 8, and 13, and are highest in volume in weeks 8 and 13. Slack messages indicating that ME students are contributing by continuing on or finishing some on-going task appear in week 5 and 7. Slack messages indicating work on a presentation are present in week 8 .

\section{Discussion}

\section{How do various aspects of the interprofessional PBSL project (e.g. it's interprofessional and service aspects) influence motivation and attitude towards course material?}

Figure 3 suggests that students maintained a fairly positive attitude toward the course throughout the semester, since they always ranked their motivation-to-excel to be high for both the class overall and the project in particular. Figure 2 suggests that interest in the technical content, opportunities to collaborate, and the perceived utility of technical content facilitated this positive attitude. This suggests that students find learning technical content intrinsically valuable and therefore have adopted a deep learning orientation with respect to the technical content ${ }^{5}$.

Different themes are dominant as motivations to excel in the class project. Fig. 2 suggests the positive attitude toward the class project seems to be due to it satisfying both egoistic and altruistic impulses. The theme "to deliver" in Figs. 4, 5, and 2 is intended to capture the expressed desire of students to show what they are capable of and/or to fulfill commitments they have made. The theme to help in Figs. 4, 5, and 2 is intended to capture the expressed desire to help others. Since the theme to deliver pertains to reputations and responsibility within an interprofessional context, the theme to deliver might be most related to the interprofessional aspect of the project. Likewise, the theme to help, which pertains not to the immediate collaborators but rather to the end-user, might be most related to the service aspect of the project. Notably, however these motivations are very underrepresented in the motivation to learn course content. Though the 
interprofessional PBSL project seems to have an ability to elicit positive attitudes from students, these attitudes do not seem to be influencing their motivation to learn. This may be because the course content and particular PBSL project are mismatched. So the students do not view course content as being instrumental to completion of the project. Therefore, one interpretation of the results is that both the interprofessional and service aspects have the capacity to influence motivation and attitude towards course material but they don't. in this case. because the interprofessional PBSL project and technical content are mismatched.

\section{How do engineering students balance interprofessional aspects of their coursework with technical aspects?}

Figure 10 evidences that most of the regular work on the project consisted of designing (e.g. in CAD) and consulting with SLP students about the designs as needed. Work done fabricating devices and Slack messages pertaining to fabrication are much more infrequent and lower in volume. This suggests a mismatch in intended outcomes and student effort since one of the intended focuses was on defining a manufacturing process that would meet the clients' manufacturing needs. This may be a consequence of focusing on the therapeutic needs of the end-user rather than the manufacturing needs of the interprofessional collaborators early on in the project. According to goal-based scenario design ${ }^{22}$, students will direct their efforts towards what the apparent goal is. In presenting students with a needs assessment of a particular end-user, the interprofessional collaboration may tacitly become a design project because engineering students will focus on designing a product to meet those needs. As far as how ME students allocated time to the interprofessional project, if the volume of messages can be assumed to be proportionate to the amount of work being done, then Fig. 7 might also be taken to suggest that much of the work was done immediately before deliverables were due (such as on week 8). This may be due to not having the project well integrated into the manufacturing curriculum such that they complimented each other rather than competing for students' time.

\section{What communication challenges do engineering students face when collaborating with SLP students on a PBSL project?}

Themes from Fig. 7 and Fig. 8 both evidence that scheduling times to meet, understanding expectations, and meeting agreed expectations were challenges to communication and collaboration. Furthermore, Fig. 11 indicates that there was not continuous communication on Slack but rather, most communication on Slack was conducted on the weeks that deliverables were due or the weeks before deliverables were due. Fig. 11 and Fig. 10 seem to indicate that work on fabrication also followed this pattern. Comparing this to Fig. 6 we see that low assessments of ME students' communication frequency and clarity by SLP students in weeks 3 and 5 correspond to challenges scheduling times to meet in weeks 3 and 5, not pinging ME students in Slack in week 3, and confusion regarding SLP expectations in week 5. Week 5 was also the week that there was an on-line interprofessional meeting which resulted in a high volume of Slack messages. So the high-volume messaging resulting from an on-line meeting seemed to result in lower assessment of collaborator communication skills. Low assessments of ME students' communication frequency and clarity by SLP students in weeks 7, and 10 correspond to a lack of communication as evidenced by Fig. 10 and Fig. 11 since neither the questionnaire data nor Slack data indicate that ME students consulted with SLP students at all during these weeks. Furthermore, Fig. 7 shows no evidence of attempted communication in weeks 7 and 10 for any of 
the ME students. Moreover, the presence of themes B and D on week 7 means that some of the ME students themselves indicated that they did not attempt to communicate and/or felt there was nothing to talk about. So the lower assessment in weeks 7 and 10 seems to be due to a lack of attempted communication. The higher assessment of ME students' communication frequency and clarity in week 8, as shown in Fig. 6, corresponds to ME students' lower than average assessment of their own communication skills, as shown in the same figure. It also corresponds to the week that ME students had to present prototypes to the SLP students in class and a high volume of communication on Slack as illustrated in Fig. 11. Fig. 7 and Fig. 8 show that the communication challenges experienced in week 8 include misunderstanding SLP expectations and challenges meeting SLP expectations as agreed. It seems that the high volume of messaging, and the in-class presentation results in a higher assessment of ME students' communication frequency and clarity. The ME students' lower assessment of their own communication skills may be due to having to clarify expectations at the last minute and challenges in meeting those expectations. One reason that a high volume of on-line messaging in week 8 corresponds to higher rating when the high volume of on-line messaging in week 5 corresponds to lower rankings may be due to the fact that the on-line messages on week 5 were en masse, not a specific line of communication between group members as they were on week 8. Week 13, which also has a high volume of messages, also corresponds to the week with the highest overall ranking of ME frequency and clarity the following week when the SLP students had to present their finished product. These messages were likely in support of the SLP students' immediate deadline, and the high ranking on week 14 was possibly influenced by the support ME students had given the SLP students.

In addition, there are some conflicts in the data that indicate that communication volume does not in itself lead to perceived communication frequency or clarity, which may be of interest for the purpose of monitoring communication in the future. Consultation with SLP students in Fig. 10 is consistent with Fig. 8 to the extent that there is always some Slack activity (reported in Fig. 8) within a week of the time that consultation with SLP was claimed in Fig. 10. However, the volume of communication exhibited in Fig. 8 is not reflected in Fig. 10. This is due to question 14 not asking for quantification of the amount of communication. However the means of quantified questions six through ten shown in Fig. 6 also do not correlate well with message volume. One possible reason for this is that the rankings are not interpreted by questionnaire recipient as a strict measure of the number of messages sent, but rather how satisfactory the amount of communication was perceived as by the questionnaire recipient. For instance, if a large amount of communication had happened the previous week when a deliverable was due but very little communication occurred the subsequent week the questionnaire recipient might not immediately lower the ranking if they did not expect a high volume of communication during that time. It is not immediately evident how to model the rationale for increasing or lowering the ranking so it is not evident what it is measuring besides the questionnaire recipient's perception. Though this is valuable in-and-of itself, it might also be advisable to put questions pertaining to strictly measurable quantities on the questionnaire which can be easily checked against other metrics as a way of verifying the accuracy of the questionnaire recipient's perceptions.

Additionally, on-line interprofessional meetings at which all groups are present should possibly be avoided. The week of such an on-line interprofessional meeting corresponded to low overall ratings of ME students' frequency and clarity of communication as indicated in Fig. 6 in spite of this week by far having the largest volume of Slack messages posted by ME students. The reason 
for this could be that having all of the different groups simultaneously participating in a single on-line session is confusing and inefficient, and students might not value interprofessional interactions that do not directly contribute to their own group projects. This is especially crucial when due dates are approaching closer. There is research to suggest that interprofessional teaching settings incorporating smaller group meetings are more effective and identifiable as more valuable by students, compared to large group meetings ${ }^{23}$.

\section{Conclusions and Future Directions}

The current action research project used a mixed methods study design to systematically investigate the effectiveness of an interprofessional PBSL project between ME and SLP students in fostering collaboration, deep learning, teamwork, and communication. Results from the current research project offer several insights towards improving the design of future learning experiences for pre-service professionals in interprofessional PBSL projects.

First, positive attitudes of ME students to the course and project throughout the semester affirms the value of interprofessional PBSL projects between ME and SLP students, which suggests a deep engagement with class content. However, the lack of attention to manufacturing in the interprofessional project and the irregular dedication of time to the project remain concerns. Additionally, while the interprofessional project has given an opportunity for ME students and SLP students to develop communication and teamwork skills, the irregular dedication of time to the interprofessional project and the lack of explicit methodology for inculcating communication and teamwork skills may undermine its effectiveness and give rise to communication challenges.

Integrating interprofessional collaboration into in-class labs and focusing on the manufacturing needs of a clinician could potentially ameliorate the lack of attention to manufacturing, the irregular dedication of time to the project. This could also help foster a a habit of interprofessional communication and teamwork. Specifically, building meeting times into class schedules would regularize students communication much in the way that may be done in a professional setting. There is prior research that suggests that integrating such routine engagements, in addition to some didactic presentations and immersive experiences, improves the effectiveness of interprofessional teams ${ }^{13}$. The change of focus to the manufacturing needs of the interprofessional collaborators should still be of significant interest to pre-professionals in health sciences due to the focus on real clinical needs ${ }^{10}$.

To add didactic presentations and immersive experiences for instruction in teamwork and communication, a faculty-led workshop may be presented at the beginning of the project. The workshop would address topics such as how shared professional expectations foster mutual respect, how to manage terms-of-art in different fields to ensure an efficient exchange of information, and how to use on-line communication tools such as Slack. In particular, the workshop could also advise students on challenges experienced in the current project, how to avoid them, and how to address them when encountered. There is evidence to show that such faculty-led communication workshops have been successful in enhancing the quality of interprofessional communication ${ }^{16}$.

Finally, though the current project has addressed an interprofessional PBSL project's 
effectiveness in fostering deep learning with respect to technical content, it has not considered student learning orientation with respect to professional skills like teamwork and communication. Since learning orientation significantly influences outcomes and it is quite possible for students to have different attitudes with regard to learning technical versus professional skills. Future work will attempt to consider both.

\section{References}

[1] A. O. T. Association et al., "Accreditation council for occupational therapy education (acote) standards and interpretive guide," Retrieved January, vol. 3, p. 2014, 2011.

[2] M. Borrego and L. K. Newswander, "Characteristics of successful cross-disciplinary engineering education collaborations," Journal of Engineering Education, vol. 97, no. 2, pp. 123-134, 2008.

[3] J. W. Creswel, "Research design: Qualitative, quantitative, and mixed methods approaches," Los angeles: University of Nebraska-Lincoln, 2009.

[4] E. Delarosa, C. Donnelly, S. Murphy, and C. Davies, "Building better together: Engineering design with occupational therapists and end users," Proceedings of the Canadian Engineering Education Association (CEEA), 2017.

[5] R. M. Felder and R. Brent, "Understanding student differences," Journal of engineering education, vol. 94, no. 1, pp. 57-72, 2005.

[6] J. E. Froyd, P. C. Wankat, and K. A. Smith, "Five major shifts in 100 years of engineering education," Proceedings of the IEEE, vol. 100, no. Special Centennial Issue, pp. 1344-1360, 2012.

[7] J. Furze, H. Lohman, and K. Mu, "Impact of an interprofessional community-based educational experience on students' perceptions of other health professions and older adults," Journal of allied health, vol. 37, no. 2, pp. 71-77, 2008.

[8] P. Gibbs, P. Cartney, K. Wilkinson, J. Parkinson, S. Cunningham, C. James-Reynolds, T. Zoubir, V. Brown, P. Barter, P. Sumner et al., "Literature review on the use of action research in higher education," Educational Action Research, vol. 25, no. 1, pp. 3-22, 2017.

[9] D. E. Giles Jr and J. Eyler, "The impact of a college community service laboratory on students' personal, social, and cognitive outcomes," Journal of adolescence, vol. 17, no. 4, pp. 327-339, 1994.

[10] C. Gilligan, S. Outram, and T. Levett-Jones, "Recommendations from recent graduates in medicine, nursing and pharmacy on improving interprofessional education in university programs: a qualitative study," BMC medical education, vol. 14, no. 1, p. 52, 2014.

[11] V. S. . C. . S. GmbH, MAXQDA, software for qualitative data analysis, 1989-2020.

[12] R. Graham, "The global state of the art in engineering education," Massachusetts Institute of Technology (MIT) Report, Massachusetts, USA, 2018.

[13] L. W. Hall and B. K. Zierler, "Interprofessional education and practice guide no. 1: developing faculty to effectively facilitate interprofessional education," Journal of interprofessional care, vol. 29, no. 1, pp. 3-7, 2015.

[14] L. M. Hayward, W. Meleis, J. Mahanna, and S. H. Ventura, "Interprofessional collaboration among physical 
therapy, speech-language pathology, and engineering faculty and students to address global pediatric rehabilitation needs: a case report," Journal of Physical Therapy Education, vol. 30, no. 4, pp. 24-34, 2016.

[15] J. L. Huff, C. B. Zoltowski, and W. C. Oakes, "Preparing engineers for the workplace through service learning: Perceptions of epics alumni," Journal of Engineering Education, vol. 105, no. 1, pp. 43-69, 2016.

[16] K. B. Keller, T. L. Eggenberger, J. Belkowitz, M. Sarsekeyeva, and A. R. Zito, "Implementing successful interprofessional communication opportunities in health care education: a qualitative analysis," International journal of medical education, vol. 4, p. 253, 2013.

[17] H. M. Matusovich, W. Oakes, and C. B. Zoltowski, "Why women choose service-learning: Seeking and finding engineering-related experiences," International Journal of Engineering Education, vol. 29, no. 2, pp. 388-402, 2013.

[18] C. on Accreditation in Physical Therapy Education, "2017 accreditation handbook: Physical therapy standards and required elements." Austin, TX: Commission on Accreditation of Athletic Training Education;, 2017.

[19] C. on Accreditation of Athletic Training Education, "2020 standards for accreditation of professional athletic training programs," Austin, TX: Commission on Accreditation of Athletic Training Education;, p. 22, 2018.

[20] R. Sagor, Guiding school improvement with action research. Ascd, 2000.

[21] L. J. Sax, A. W. Astin, and J. Avalos, "Long-term effects of volunteerism during the undergraduate years," The review of higher education, vol. 22, no. 2, pp. 187-202, 1999.

[22] R. C. Schank, A. Fano, B. Bell, and M. Jona, "The design of goal-based scenarios," The journal of the learning sciences, vol. 3, no. 4, pp. 305-345, 1994.

[23] V. Schwarzbeck, J. Hundertmark, K. Wipfler, C. Mahler, S. Frankenhauser, and J.-H. Schultz, "Suggestions for interprofessional educational courses from a students' perspective-a qualitative study," GMS Journal for Medical Education, vol. 36, no. 1, 2019.

[24] L. J. Shuman, M. Besterfield-Sacre, and J. McGourty, "The abet "professional skills"—can they be taught? can they be assessed?" Journal of engineering education, vol. 94, no. 1, pp. 41-55, 2005.

[25] L. Springer, M. E. Stanne, and S. S. Donovan, "Effects of small-group learning on undergraduates in science, mathematics, engineering, and technology: A meta-analysis," Review of educational research, vol. 69, no. 1, pp. 21-51, 1999.

[26] J.-W. Strijbos and G. Stahl, "Methodological issues in developing a multi-dimensional coding procedure for small-group chat communication," Learning and Instruction, vol. 17, no. 4, pp. 394-404, 2007.

[27] P. T. Terenzini, A. F. Cabrera, C. L. Colbeck, J. M. Parente, and S. A. Bjorklund, "Collaborative learning vs. lecture/discussion: Students' reported learning gains," Journal of Engineering Education, vol. 90, no. 1, pp. 123-130, 2001.

[28] C. B. Zoltowski and W. C. Oakes, "Learning by doing: reflections of the epics program," International Journal for Service Learning in Engineering, Humanitarian Engineering and Social Entrepreneurship, pp. 1-32, 2014. 